\title{
The influence of chloride ion concentration on the localized corrosion of E717 Mg alloy
}

\author{
Christos Kousis*, ${ }^{*}$ Neil McMurray*, Patrick Keil**, Geraint Williams* \\ *Materials Research Centre, College of Engineering, Swansea University Bay Campus, Crymlyn Burrows, Swansea, SA1 8EN, \\ U.K.
}

**BASF Coatings GmbH, Glasuritstrasse 1, 48165 Münster, Germany

‡Corresponding author: E-mail: 922387@swansea.ac.uk, Materials Research Centre, College of Engineering, Swansea University Bay Campus, Crymlyn Burrows, Swansea, SA1 8EN, U.K.

\section{ABSTRACT}

The localized corrosion behavior of E717 magnesium alloy immersed in chloride-containing electrolyte is investigated using an in-situ scanning vibrating electrode technique (SVET), coupled with time-lapse imaging (TLI). It is shown that initiation of localized corrosion in chloride-containing electrolyte is characterized by the appearance of discrete local anodes, corresponding with the leading edges of dark, filiform-like features, which combine with time to produce a mobile anodic front. The size and growth rate of these features are highly dependent on the chloride ion concentration of the electrolyte. SVET-derived current density maps reveal that the corroded surface left behind the anodic front is cathodically activated, where cathodic current density values progressively decline with increasing distance away from the anodic leading edge. The intensity of localized anodes is highly dependent on the chloride ion concentration, where progressively higher local anodic current density values are observed with increasing chloride ion concentration along with progressively higher rates of volumetrically-determined hydrogen evolution. Breakdown potential, measured using time-dependent free corrosion potential transients and potentiodynamic polarization at neutral and elevated $\mathrm{pH}$ respectively, is shown to vary with the logarithm of chloride ion concentration and the time for localized corrosion initiation is progressively increased with decreasing chloride concentration. From the combination of results which are presented herein, the underlying reasons for the influence of chloride ion concentration on the localized corrosion characteristics of E717 alloy will be discussed.

KEY WORDS: Chloride, Free Corrosion Potential, Hydrogen Evolution, Localized Corrosion, Magnesium Alloys, Scanning Vibrating Electrode Technique

\section{INTRODUCTION}

Magnesium and its alloys are one of the lightest engineering metals and recently there has been an increasing interest on widening their use especially in applications were weight reduction is essential. When compared with other engineering metals, magnesium is $35 \%$ lighter than aluminium and $75 \%$ lighter than steel ${ }^{1}$. Although magnesium alloys have attractive properties like good conductivity and castability as well as adequate strength-to-weight ratio, they also have high chemical reactivity and low open circuit potential (-1.6 $\left.\mathrm{V}_{\text {sce }}\right)$ making them prone to galvanic corrosion which has hindered their widespread use in many applications where such properties are important. Researchers in the Multi-Material Lightweight Vehicle project proposed the reduction of the weight of the 2013 Ford Fusion vehicle by $50 \%$ with the Mach II design which primarily incorporates $\mathrm{Mg}$ alloys into the subframes, closures and chassis ${ }^{2}$. A current candidate for these types of applications is the E717 magnesium alloy (also known as ZE10A or ZEK100 type alloy), which contains small quantities of the rare earth element neodymium (Nd), along with zirconium (Zr) and zinc (Zn). Mg alloys containing rare earth (RE) elements have been the centre of interest lately due to the beneficial effect of the RE additions on 
both mechanical properties and corrosion resistance of Mg alloys. RE additions can improve the creep resistance ${ }^{3,4}$ of $\mathrm{Mg}$ alloys and from a corrosion perspective they have the useful advantage of improving grain refinement ${ }^{5-8}$ which in turn is proposed to reduce corrosion rate by limiting the size of noble beta phase particles, such as Fe rich particles. Recent comparative studies of widely used AZ alloy types with prototype alloys of similar composition to $\mathrm{E} 717^{9,10}$, have demonstrated improved corrosion resistance, which the authors attribute to a decreased cathode-to-anode area ratio within the microstructure of these alloys and a lower difference in the relative nobility between the principal second phases and the Mg matrix.

Much of the preliminary work in assessing the corrosion behaviour of E717 alloy has been carried out with a view to its use in biodegradable implants for weight bearing bones, where both in-vivo ${ }^{11}$ and in-vitro ${ }^{12}$ studies demonstrated a promising combination of mechanical strength and corrosion resistance. However, subsequent long-term studies, identifying possible pathological effects on the host tissue has raised questions regarding the suitability of E717 in such bio-material related applications ${ }^{13,14}$. A combination of post-corrosion electron microscopy characterisation and micro computed tomography (CT) examination was used to quantify the extent of alloy degradation. Despite the lack of mechanistic information on E717 corrosion, such studies have shown how the behaviour of E717 in simulated saline-based environments can be greatly modified by the presence of other ionic species such as calcium cations and phosphate anions, which are able to both form insoluble surface films and moderate pH $12,15,16$.

Recent investigations of E717 corrosion behaviour in more conventional, unbuffered sodium chloride aqueous test solutions demonstrated that the alloy is affected by filiform-like corrosion ${ }^{17,18}$, which takes the form of discrete individual tracks at low $\mathrm{Cl}^{-}$concentration, but covers significantly larger areas of the exposed surface at higher concentration ${ }^{17}$. Scanning electron microscopy-based investigation of the microstructure identified several intermetallic phase type, including tertiary Mg-Zn-Nd (T-phase), Zn-Zr and Fe-containing Zr along with discrete Zr particles ${ }^{17}$. From experiments carried out in pure water, it was concluded that the Fe-containing Zr particles acted as local cathode sites during the corrosion of E717 alloy. Others have studied the influence of chloride ions concentration on the properties of the surface film formed on E717 under immersion conditions ${ }^{19,20}$. In comparison to a dense bilayered film, consisting of an inner $\mathrm{MgO}$ layer and an outer $\mathrm{Mg}(\mathrm{OH})_{2}$ film formed in water, the presence of high $\mathrm{Cl}^{-}$concentration produces a significantly thicker, nano porous outer layer ${ }^{19}$. Chloride ion penetration into the inner $\mathrm{MgO}$-base layer was detected at high concentrations of $\geq 1 \% \mathrm{w} / \mathrm{v}$ by using a combination of SEM and STEM, but not after immersion in more dilute concentration of 0.01 $\% \mathrm{w} / \mathrm{v}^{20}$, although the authors report a different growth mechanism within the dense $\mathrm{MgO}$ base layer. In addition, a recently published investigation of organic coated E717 surfaces demonstrated that filiform-like features propagated underneath the polymer layer when corrosion was initiated at a penetrative coating defect by the application of $\mathrm{MgCl}_{2}$ or $\mathrm{HCl}(\mathrm{aq})^{21}$. However, the work also identified an apparent cathodically-driven coating disbondment mechanism which occurred when underfilm corrosion was initiated using group I chloride salts ${ }^{21}$.

From the current scientific literature dealing with the corrosion of E717, it is evident that relatively little electrochemical characterisation of its corrosion behaviour has been carried out to date. The principal aim of this work is to address the lack of work in this area by using a combination of conventional potentiostat-based studies along with in-situ scanning vibrating electrode technique (SVET) analysis of E717 in a range of chloridecontaining electrolytes. The intention is twofold; firstly to determine the influence of chloride concentration on the breakdown of temporary passivity in E717 and secondly determine its effect on the kinetics of previously observed filiform-like corrosion ${ }^{17}$ along with the magnitude of current density distributions associated with this phenomenon. Filiform-like corrosion is known to propagate on several technologically important Mg alloys, such as $\mathrm{AZ31}{ }^{22-24}, \mathrm{AZ61}{ }^{23}$ and AZ91 ${ }^{22,25}$ alloy and is also observed for commercially pure $\mathrm{Mg}$ in certain inter-related chloride ion concentration and pH ranges 26-28. SVET has been used in several previous studies to visualise the localized corrosion features connected with filiform-like corrosion initiation and propagation ${ }^{24,27-31}$. In most of these investigations, the leading edges of the filiform tracks are shown to be intense local anodes, while the remainder of the dark surface left behind is cathodically activated with respect to the intact surface. For commercial purity $\mathrm{Mg}$, the cathodic activation of the 
previously corroded surface is thought to originate from accumulation of iron rich impurity phases caused by the dissolution of the Mg matrix ${ }^{27,28,31}$. However, there is also significant evidence that suggests a contribution due to re-plating of iron ions generated by self-corrosion of impurity particles which become electrically detached from the matrix ${ }^{31-33}$. In the case of filiform-like corrosion affecting AZ31, an accumulation of noble Al-Mn-(Fe) has been suggested as the principal cause of enhanced cathodic activity ${ }^{24}$. By using a similar approach, this particular investigation seeks to confirm whether this type of localized corrosion mechanism occurs for freely corroding E717 alloy surfaces and how the [Cl-] influences the characteristics of any observed localized corrosion. The present work was conducted by using in-situ SVET coupled with time-lapse imaging (TLI), which enables simultaneous correlation of visual macroscopic corrosion features with corresponding current density distribution maps. The combination has recently been employed in an investigation of localized corrosion behaviour of zinc alloy coated steel ${ }^{34}$ and the work described here represents the first report of its use in the characterisation of Mg alloy corrosion behaviour.

A final aim of this work is to determine the influence of chloride ion concentration on the initiation of localized corrosion of E717. Several recent publications have employed combinations of potentiodynamic polarisation, hydrogen evolution measurements and electrochemical impedance spectroscopy (EIS) to quantify the effect of changes in $\left.\mathrm{Cl}^{-}\right]$and $\mathrm{pH}$ on the corrosion behaviour of various $\mathrm{Mg}$ alloys ${ }^{35-39}$. Typically, these works indicate that increasing $\left[\mathrm{Cl}^{-}\right]$produces higher rates of corrosion, but do not address the relationship between corrosion initiation resulting from the breakdown of temporary passivity and the $\left[\mathrm{Cl}^{-}\right]$of the electrolyte. Recent published work, using a new method of establishing a breakdown potential $\left(E_{b}\right)$ value for both pure $M g$ and $A Z 31$ alloy by monitoring time-dependent free corrosion potential behaviour ${ }^{40}$, demonstrated that $E_{b}$ varied as a function of $-\log _{10}\left[\mathrm{Cl}^{-}\right]$. The findings obtained under freely corroding conditions were confirmed using conventional potentiodynamic experiments for the same specimens immersed at elevated $\mathrm{pH}$, where well-developed passive regions were observed in the anodic branches of their polarisation curves. In this work we use the same combination of methodologies to investigate whether or not a similar relationship linking $\mathrm{E}_{\mathrm{b}}$ to [Cl] also exists for E717 immersed in different chloride containing electrolytes.

\section{EXPERIMENTAL DETAILS}

The Mg alloys which were used in this work are the E717 (ZEK100) and the AZ31. The E717 specimens were provided by Chemetall GmbH which came as sheets and were cut in $2 \mathrm{~mm}$ thick coupons of $50 \mathrm{~mm}$ squares using an EDM machine. The E717 has a nominal composition (all weight $\%): 1.25 \% \mathrm{Zn}, 0.5 \% \mathrm{Zr}, 0.22 \% \mathrm{Nd}, 0.008 \% \mathrm{Cu}, 0.004 \% \mathrm{Fe}, 0.3 \%$ others, balance $\mathrm{Mg}$, and $\mathrm{F}$ temper. The AZ31 specimens were supplied by Magnesium Elektron Ltd and were machined from as-cast ingots in $50 \mathrm{~mm}$ squares with a nominal composition of (all weight \%) $3.1 \% \mathrm{Al}, 0.7 \% \mathrm{Zn}, 0.24 \% \mathrm{Mn}$; with balance Mg. Prior to testing, the samples were subjected to grinding using silicon carbide paper (up to a 1200 grit surface finish) (Buehler CarbiMet ${ }^{\mathrm{TM}}$ ) and rinsed with distilled water and ethanol. The electrolytes $\left(10^{-3} \mathrm{M}\right.$ to $\left.3.7 \mathrm{M} \mathrm{NaCl}\right)$ used in all experiments were prepared using distilled water and analytical grade reagents (Aldrich Chemical Co.). In the case of immersion experiments involving SVET, the abraded samples were covered with 90 $\mu \mathrm{m}$ thick extruded PTFE 5490 tape (3M Ltd.) leaving only a square area of $6 \times 6 \mathrm{~mm}$ exposed in the centre of the sample, which then immersed in the aqueous electrolyte. The same sample preparation procedure was adopted for the potentiodynamic experiments, open circuit potential (OCP) and hydrogen gas evolution measurements although an exposed area of $10 \times 10 \mathrm{~mm}$ square was used for the potentiodynamic experiments. A conventional 3 electrode setup with a Solartron 1280B Workstation was used for the potentiodynamic experiments comprising a saturated calomel reference (SCE) electrode and a $1 \mathrm{~cm}^{2}$ area platinum gauge counter electrode. 
The hydrogen gas evolution from corroding E717 and AZ31B magnesium alloy surfaces was collected volumetrically by using a $10 \pm 0.02$ $\mathrm{cm}^{3}$ capacity, conically ended burette which was placed on top of the sample with the conical end facing the exposed area positioned at a minimal distance from the surface to avoid hydrogen escaping. After pouring the test electrolyte into a beaker, a plastic syringe was attached at one end of the burette and the electrolyte was drawn upwards to an appropriate graduation mark on the burette, whereupon the tap was closed. During hydrogen gas evolution from the immersed Mg alloy, surface the electrolyte volume decreased accordingly by displacing the electrolyte, and the change in volume recorded every 10 minutes.

The scanning vibrating electrode measurements were conducted using a $125 \mu \mathrm{m}$ diameter platinum micro-disc electrode, encased in a glass sheath, vibrating at a frequency of $140 \mathrm{~Hz}$. A detailed description of the instrumentation employed, and the calibration methodology can be found elsewhere ${ }^{41,42}$, with the exception of the addition of the endoscope. The combination of SVET and time-lapse imaging was achieved using a waterproof endoscope (Supereyes Y002) as described previously ${ }^{34}$, which enables simultaneous capture of current density maps with corresponding photographic images. The waterproof microscope endoscope was attached to the SVET probe vibrator assembly by using a 3D printed arm with a grub screw arrangement to secure the endoscope. The SVET probe scanned areas of $36 \mathrm{~mm}^{2}$ at a probe-to-sample height of $100 \mu \mathrm{m}$ using a data point density of 5 points per $\mathrm{mm}$ in both $\mathrm{x}$ and $\mathrm{y}$ directions. SVET scans were carried out immediately following immersion and then at intervals of 10 minutes and thereafter for periods of up to $24 \mathrm{~h}$, taking 144 scans in total and each SVET scan taking around 5 minutes to complete. After the competition of one scan, the SVET head was automatically moved to a rest position and the endoscope camera was moved directly over the sample surface where it could record full surface images to correlate with the SVET current density distribution maps.

\section{RESULTS AND DISCUSSION}

\subsection{Characterisation of localized corrosion propagation}

A series of in-situ experiments employing combined SVET-TLI were conducted by immersing E717 specimens in naturally aerated NaCl (aq) containing solutions over a range of concentrations at $\mathrm{pH} 6$ in order to characterise localized corrosion behaviour. When very dilute concentrations of $\leq 10^{-3} \mathrm{M}$ were used, there was no evidence of passivity breakdown within $12 \mathrm{~h}$ of immersion and the exposed surface was shown to be largely inert with no clear evidence of discrete local anode and cathode regions. However, when the $\mathrm{NaCl}$ concentration was increased, breakdown of passivity leading to the propagation of a dark film, taking the form of filiform-like corrosion features were observed. A series of current density $\left(\mathrm{j}_{2}\right)$ distribution maps, along with associated photographic images correlating the visual corrosion features with the active local anode and cathode regions at various immersion times, is shown in Figure 1 for an $\mathrm{E} 717$ specimen immersed in $0.034 \mathrm{M} \mathrm{NaCl}(\mathrm{aq})$ at $\mathrm{pH} 6.5$.

During the first stages of the immersion and before the surface breakdown, the surface is largely electrochemically inert with some evidence of broad, weakly anodic areas coupling with local cathodic regions $\left(-1.0<\mathrm{j}_{2}<0 \mathrm{~A} \mathrm{~m}^{-2}\right)$ in a similar manner to the early stages of the corrosion pure $\mathrm{Mg}{ }^{24,42}$. At this point, it is believed that an imperfect $\mathrm{Mg}(\mathrm{OH})_{2}$ film grows on the surface, caused when $\mathrm{Mg}^{2+}$ ions produced by the initial anodic dissolution combined with hydroxide anions generated by the corresponding hydrogen evolution cathodic reaction. At the time of the breakdown of the surface, a black spot appears which can be seen in Figure 1a (black arrow) which coincides with a region of intense net anodic activity ( $\mathrm{j}_{\mathrm{z}}$ ca. $5 \mathrm{~A}$ $\mathrm{m}^{-2}$ ) observed on the corresponding current density map. 
It should be borne in mind that the size of a corrosion feature revealed by the SVET does not necessarily reflect its physical size and this can be explained in terms of the limited lateral resolution of the technique. The signal peak width at half maximum (whm) is related to the probe height which in this case was $100 \mu \mathrm{m}$. Isaacs ${ }^{43}$ has shown that the SVET will record a whm of $1.533 \mathrm{~h}$ (where $\mathrm{h}=\mathrm{scan}$ height or probe-to-sample distance) and since the $\mathrm{h}$ in this experiment is $100 \mu \mathrm{m}$ and the diameter of the SVET micro-disk is $125 \mu \mathrm{m}$, the total whm will be approximately 250 $\mu \mathrm{m}$. This limit in spatial resolution indicates that the SVET will not be able to resolve features separated by a distance less than $0.27 \mathrm{~mm}$. So, the size of anode as revealed by SVET does not reflect the physical size of the anode due to the spatial resolution limitation of the SVET which makes it appear larger. Over the $2 \mathrm{~h}$ period which follows this point of breakdown a network of black tracks appears to emanate from this point on the exposed E717 surface, where active anodes are located at the mobile leading edges of these tracks. After 250 minutes, individual local anodes coalesce into a 2 mm wide "front" moving along the surface consuming the previous intact surface, while measured $\mathrm{j}_{\mathrm{z}}$ values have increased to values of ca. $+15 \mathrm{~A} \mathrm{~m}^{-2}$. By comparing the SVET-derived color-scale $\mathrm{j}_{\mathrm{z}}$ maps and the photographic images at the same immersion times, the anodes are seen to coincide with the front of the corrosion tracks where hydrogen bubble streams are seen to originate. It is also evident, especially in Figure $1 \mathrm{~d}$, where the localized corrosion feature traverses from top to bottom of the scan area, that the corroded area left behind the advancing anodic front is cathodically activated with respect to original intact surface, evidenced by $\mathrm{j}_{z}$ values of between -2 and $-3 \mathrm{~A} \mathrm{~m}^{-2}$ measured on the right hand side of the scan area. After the entire surface is covered with corrosion product (Figure 1e), the number of active anodes has markedly increased. However, it is also clear that the cathodic activation of the previously corroded areas is a temporary phenomenon and that the current density values associated with these regions decrease with time. For example, a comparison of Figures $1 \mathrm{e}$ and $1 \mathrm{f}$ shows that typical current density values of ca -2 to $-3 \mathrm{~A} \mathrm{~m}^{-2}$ have decreased to $<1 \mathrm{~A} \mathrm{~m}^{-2}$ during the intervening $8 \mathrm{~h}$ period between these 2 scans. It is proposed that the de-activation of local cathode sites occurs due to two possible effects. Firstly, $\mathrm{Mg}(\mathrm{OH})_{2}$ deposition and the progressive thickening of a corrosion product film in these areas, due to the elevated local $\mathrm{pH}$ will produce a more effective barrier to interfacial electron transfer, which will slowly cause previously cathodically activated areas to become progressively more electrochemically inert. Additionally, in order for local anodes to continue their propagation over the surface, there is a need for coupling with the cathodically-activated corroded regions. This can only occur over finite distances primarily depending on the conductivity of the solution. So as local anodes move further away from their original locations, the cathodically activated corroded surface produced by prior anodic dissolution in these regions will necessarily de-activate because coupling with remote local anodes will become ohmically limited.

Figure 2 shows a selection of $\mathrm{j}_{\mathrm{z}}$ distribution maps and corresponding visual images obtained for an E717 specimen freely corroding in a more concentrated $0.17 \mathrm{M} \mathrm{NaCl}(\mathrm{aq})$ solution. Although the localized corrosion features resemble those shown in Figure 1 , there are some differences, especially in terms of the propagation of dark corrosion product. In this more concentrated electrolyte, there is less evidence of discrete filiform-like tracks and consequently the features comprise more uniform regions which consume the intact surface more rapidly than previously observed in Figure 1. At this higher concentration, the entirety of the exposed surface became covered with a black film within 500 min of immersion, whereas previously this occurred within 900 min immersion period. It is also evident that the peak values of both anodic and cathodic values are significantly higher, with the more concentrated electrolyte, with typical values of $+70 \mathrm{~A} \mathrm{~m}^{-2}$ and $-5 \mathrm{~A} \mathrm{~m}^{-2}$ respectively. The more rapid conversion of the intact surface appears related to the fact that individual propagating anodes rapidly combine to form a unified front which propagates across the entirety of the width of the exposed surface (see Figure $2 \mathrm{c}$ and $2 \mathrm{~d}$ ). Again, there is clear evidence of cathodic activation of the previously anodically attacked surface left behind the advancing anodic front. However, it is also apparent that the most active local cathodes follow immediately behind the areas of anodic activity as shown in Figure $2 \mathrm{c}$ and $2 \mathrm{~d}$. As the anodic front moves further away from its original location, peak cathodic $\mathrm{j}_{\mathrm{z}}$ values of up to $-4 \mathrm{~A} \mathrm{~m}^{-2}$ measured in the region immediately to the its left hand size (indicated by the dashed circle), decrease to ca. $-1 \mathrm{~A} \mathrm{~m}^{-2}$ over an ensuing 40 min period. At longer immersion times, when the exposed surface is fully corroded and occupied by a black corrosion-induced film, several local anodic regions simultaneously travel backwards and forwards across the previously corroded surface, and leave a temporary cathodically activated 
zone, extending ca $1 \mathrm{~mm}$ behind in their wake (see Figure 2f). The current density distributions associated with the propagating corrosion front observed in Figures $2 \mathrm{c}$ and $2 \mathrm{~d}$ can perhaps be better understood in terms of the line profiles of $\mathrm{j}_{\mathrm{z}}$ versus distance (Figure 3 ) extracted from regions of the SVET-derived $j_{z}$ maps indicated by the dashed horizontal arrows. As the anodic front characterised by peak $j_{z}$ values in the +25 to +35 A m ${ }^{-2}$ range in moves from left to right, a $2 \mathrm{~mm}$ local cathodic region behind develops to its left-hand side, where $\mathrm{j}_{\mathrm{z}}$ values of between -2 and $-3 \mathrm{~A} \mathrm{~m}^{-2}$ are measured. The intact surface to the right of the local anode region is shown to be electrochemically inactive $\left(\mathrm{j}_{2} \leq \pm 0.1 \mathrm{~A} \mathrm{~m}{ }^{-2}\right)$.

Figure 4 shows the current density maps with the corresponding images which were obtained by immersing the same alloy in a $0.86 \mathrm{M}$ $\mathrm{NaCl}$ solution. In this much more concentrated electrolyte, breakdown occurs within 15 min of immersion (in this case in the top left corner of the exposed area) followed by propagation of filiform-like dark tracks into the centre of the scan area (See Figure 4a). Individual tracks rapidly coalesce to form an anodic front which rapidly sweeps across the intact surface until, after $5 \mathrm{~h}$, the entirety of the surface becomes covered with a dark corroded film. As observed in Figures 1 and 2, the dark corroded surface affected by anodic dissolution becomes cathodically activated with respect to the intact surface. In this case typical cathodic current density values measured immediately behind the advancing anodic front (see Figure 4c) are generally higher (ca. $-5 \mathrm{~A} \mathrm{~m}^{-2}$ ) than those observed in less concentrated electrolyte. Significantly higher current density values (of up to $+100 \mathrm{~A} \mathrm{~m}^{-2}$ ) compared to those measured at lower $\mathrm{NaCl}(\mathrm{aq})$ concentrations area also observed for the active anodes which subsequently traverse the fully corroded surface (Figures $4 \mathrm{~d}-\mathrm{f}$ ). Their positions of these highly intense focal anodes can be correlated with regions which evolve rising streams of fine $\mathrm{H}_{2}$ bubbles, characterised by cloudy white features observed to the right-hand side of Figure $4 \mathrm{f}$. Although it seems that new anodic sites are emerging from previously cathodic sites (Figure 1f, 2f, 4d), this is not the case since it is the same anode which initially appeared on the surface which later breaks apart to create an anodic front. The anodes which comprise the anodic front can change their formation giving the impression that new anodic sites have emerged on the surface.

A comparison of the results presented in Figures 1, 2 and 4 shows that progressively increasing the sodium chloride concentration produces the following effects.

(i) More rapid propagation of localized corrosion as characterised by the development of a black film which consumes the intact surface and in time covers the whole exposed scanned area.

(ii) A transition from discrete filiform-like dark tracks to larger corrosion features, resembling dendrites, which produce a unified corrosion front which traverses the exposed alloy surface.

(iii) A progressive increase in current density values associated with both local anodic regions along with cathodically activated areas corresponding to dark corroded areas produced by previous anodic dissolution.

The influence of $[\mathrm{NaCl}]$ on the propagation of localized corrosion can perhaps be better understood by quantifying the area occupied by dark corrosion product, carried out using image analysis of the time-lapse photographs, which is plotted as a function of immersion time in Figure 5. The results for each concentration show 2 discrete phases, which when correlated with each separate time-lapse sequence, shows an initial slower phase corresponding to the propagation of discrete filiform tracks which subsequently transforms to a faster process where a unified corrosion front moves across the E717 surface. The point of transition appears to correspond with the time at which discrete local anodes combine, which for a 0.86 $\mathrm{M}$ concentration occurs at an immersion period of ca. $2 \mathrm{~h}$ and progressively lengthens to $\mathrm{ca}$. $5 \mathrm{~h}$ as $[\mathrm{NaCl}]$ is decreased to $0.034 \mathrm{M}$. For phase 1 , the slopes of the area vs time plots decrease from $0.04 \mathrm{~mm}^{2} / \mathrm{min}$ to $0.025 \mathrm{~mm}^{2} / \mathrm{min}$ over the [NaCl] range studied here. The slopes of corroded area vs time plots in phase 2 are significantly higher, but show a more marked dependence on $[\mathrm{NaCl}]$ and are seen to progressively decrease from 0.17 to 0.11 and $0.06 \mathrm{~mm}^{2} / \mathrm{min}$ for concentrations of $0.86,0.17$ and $0.034 \mathrm{M}$ respectively. It therefore seems that an autocatalytic effect may be present 
under conditions where discreate filaments coalesce, causing the corrosion feature thus formed to propagate more rapidly. A similar observation has been made for the localized corrosion of an AZ31 welded specimen immersed in $5 \% \mathrm{w} / \mathrm{v} \mathrm{NaCl}(\mathrm{aq}){ }^{30}$, where velocities of ca. $0.05 \mathrm{~mm} / \mathrm{min}$ measured for discrete filaments increased by $50 \%$ after these had coalesced into a large localized corrosion feature.

Observations made regarding the role of $[\mathrm{NaCl}]$ in controlling morphologies of localized corrosion features affecting E717 are generally in line with previous investigations involving pure $\mathrm{Mg}{ }^{28}$ and $\mathrm{AZ31}{ }^{24}$. Disc-like propagation of the dark corrosion product film on pure Mg observed in highly concentrated electrolyte, which transforms to filiform-like in significantly more dilute $\mathrm{NaCl}$ (aq) solutions ${ }^{28}$, was ascribed to a decrease in throwing power, where coupling of local anodes with cathodically activated corroded regions became limited to progressively smaller distances over the exposed surface. It is likely that the observations made here regarding the increased velocity of corrosion front propagation, coupled with progressively higher local anodic current densities measured in more concentrated electrolyte, can also be explained using the same argument regarding ohmically-controlled localized corrosion. However, it should also be noted that chloride ions are also known to increase the solubility of $\mathrm{Mg}(\mathrm{OH})_{2}{ }^{40}$ and therefore at higher concentrations could disfavour corrosion product deposition on local cathodic sites. Consequently, local cathode activity may become significantly prolonged at high chloride concentrations, in turn driving more anodic dissolution at the leading edges of the filiform like features. Another question to address is the origin of the cathodic activation of the corroded surface produced by previous anodic dissolution as clearly demonstrated in Figures 1 - 4. A previous SVET investigation of AZ31, which demonstrated the same behaviour in this alloy, albeit with significantly higher cathodic $j_{z}$ values of up to $-10 \mathrm{~A} \mathrm{~m}^{-2}$ proposed that the cathodic activation was caused by an accumulation of noble Al$\mathrm{Mn}$ (Fe) particles remaining in electrical contact with the matrix within the regions affected by filiform-like attack ${ }^{24}$. Subsequent physical characterisation of cathodically activated regions of the corroded AZ31 surface confirmed the presence of such particles embedded in the filament region, but also revealed the formation of a $\mathrm{Zn}$-enriched $\mathrm{Mg}$ solid at the metal/corrosion film interface ${ }^{44}$. It seems plausible therefore to postulate that the cathodic activation observed for corroding E717 is caused by enrichment in noble particles such as Fe-containing Zr, demonstrated by others ${ }^{17}$ to be the most active sites for hydrogen evolution. Others however, have recently demonstrated enhanced rates of cathodic hydrogen evolution on hydroxide covered magnesium, compared with a pristine $\mathrm{Mg}$ surface ${ }^{45}$, and therefore the $\mathrm{Mg}(\mathrm{OH})_{2}$ corrosion product formed on the filament tracks may also play a role in producing a cathodically activated region.

The data in Figures 1, 2 and 4 may be conveniently quantified and summarised by numerically integrating the time-dependent $j_{z}$ distribution maps in a manner described previously ${ }^{42}$. Figure 6 shows the variation of area-normalised, total integrated anodic current $\left(\mathrm{J}_{\mathrm{a}}\right)$ with respect to immersion time, determined at 3 different $\mathrm{NaCl}(\mathrm{aq})$ concentrations. The differences in the magnitude of the time-dependent $\mathrm{J}_{\mathrm{a}}$ values in plots $\mathrm{i}-\mathrm{iii}$ demonstrate the progressively higher localized corrosion rates measured with increasing electrolyte concentration. At a concentration of $0.86 \mathrm{M}$, fluctuating values of $\mathrm{J}_{\mathrm{a}}$ observed during the initial filiform-like propagation phase eventually stabilise at a value of ca $1.5 \mathrm{~A} \mathrm{~m}{ }^{-2}$ after $8 \mathrm{~h}$ immersion, when the entire exposed area is covered by dark corrosion product. Plot ii obtained for a $0.17 \mathrm{M} \mathrm{NaCl}$ (aq) concentration shows that $\mathrm{J}_{\mathrm{a}}$ values stabilise at a lower values of ca $0.8 \mathrm{~A} \mathrm{~m}^{-2}$, while the lowest concentration of $0.034 \mathrm{M}$, plot iii demonstrates that $\mathrm{J}_{\mathrm{a}}$ becomes non-zero after an immersion time of $7 \mathrm{~h}$, after the breakdown of temporary passivity has occurred, thereafter progressively rising to a relatively constant value of $0.6 \mathrm{~A} \mathrm{~m}^{-2}$ following a further $10 \mathrm{~h}$ immersion period. By converting each value of $\mathrm{J}_{\mathrm{a}}$ to charge and summing these individual values over a $24 \mathrm{~h}$ immersion period, a Mg mass loss estimate can be calculated for each $\mathrm{NaCl}(\mathrm{aq})$ concentration, using Faraday's law. Using this approach, values of mass loss through localized concentration of $14.0,8.6$ and $3.6 \mathrm{~g} \mathrm{~m}^{-2}$ day $^{-1}$ for $\mathrm{NaCl}(\mathrm{aq})$ concentrations of $0.86,0.17$ and $0.034 \mathrm{M}$ respectively can be determined. 


\subsection{Characterisation of chloride concentration effects on passivity breakdown}

From the immersion experiments carried out in section 3.1, it is evident that chloride concentration plays an important role in the initiation of filiform-like corrosion. The time taken for breakdown to occur is seen to lengthen considerably with progressively more dilute concentrations, until a point is reached (at $\leq 10^{-3} \mathrm{M}$ ) where no filiform-like is observed over a $24 \mathrm{~h}$ immersion period. Previously published work, using both pure Mg and AZ31, demonstrated that monitoring time-dependent free corrosion potentials following initial immersion could provide a means of determining a breakdown potential $\left(E_{b}\right)$ under circumstances where spontaneous breakdown is observed in the absence of external polarization ${ }^{40}$. The variation of free corrosion potential ( $\left.\mathrm{E}_{\text {corr }}\right)$ with time observed during the immersion of an $\mathrm{E} 717$ surface in $0.17 \mathrm{M} \mathrm{NaCl}(\mathrm{aq})$ at pH 6 is given in Figure 7 (a). In addition, SVET-derived current density distribution maps and associated close up visual images, given in Figures 7(b) and 7(c), allow features of the $E_{\text {corr }}$ transient to be correlated with visualisations of localized corrosion behaviour. Immediately after immersion, but before any visible evidence of filiform-like initiation, $E_{\text {corr }}$ rises with time over $100 \mathrm{~min}$ from an initial starting potential of $-1.7 \mathrm{~V}_{\mathrm{SCE}}$. At a point where a localized corrosion feature is first observed, characterised by the appearance of a dark spot which evolves a rising stream of fine $\mathrm{H}_{2}$ bubbles, $\mathrm{E}_{\text {corr }}$ decreases sharply from a maximum of $-1.60 V_{S C E}$ as shown by the arrow linking Figure $7 b$ to the $E_{c o r r}$ vs time plot. From the associated SVET $j_{z}$ distribution map, the location where breakdown occurs is revealed as an intense focal anode, and as such the sharp decrease in $\mathrm{E}_{\text {corr }}$ to more negative values can be explained in terms of mixed potential theory, where the corresponding cathodic current will rise in order to preserve electroneutrality.

The initial rise in $E_{\text {corr }}$ has been explained previously in terms of a period of magnesium hydroxide $\left(\mathrm{Mg}(\mathrm{OH})_{2}\right)$ film growth, producing temporary passivity and thus causing $\mathrm{E}_{\text {corr }}$ to become more positive ${ }^{40}$. The maximum point of the $\mathrm{E}_{\text {corr }}$ vs time transient, prior to its sharp decrease by ca. $20 \mathrm{mV}$ is identified as a breakdown potential $\left(\mathrm{E}_{\mathrm{b}}\right)$, which when reached induces initiation of filiform-like as highly localized anodic attack occurs at a weak point in the imperfect $\mathrm{Mg}(\mathrm{OH})_{2}$ surface film formed over the first 100 min of immersion. Figure 7 (c) shows the appearance of the corroding E717 surface, along with its appropriate current density distribution observed ca. 180 min following breakdown, where filiform like features, characterised by intense anodic leading edges and cathodically activated dark tracks has started to propagate over the upper top left quadrant of the exposed surface. During this stage, the $E_{\text {corr }}$ vs time plot shows significantly more superimposed noise (ca. $\pm 1 \mathrm{mV}$ ), presumably resulting from perturbations caused by hydrogen bubble formation and release from actively corroding, filiform-like affected regions.

Further experiments were subsequently carried out using a series of $\mathrm{NaCl}$ (aq) concentrations in the $0.034 \mathrm{M}$ to $3.4 \mathrm{M}$ range to investigate the influence of $\left[\mathrm{Cl}^{-}\right]$on the apparent breakdown potential $E_{b}$, determined by monitoring changes in the $E_{\text {corr }}$ versus time transient. Typical $E_{c o r r}$ versus time curves obtained for E717 specimens at $\mathrm{pH} 6$ for concentrations ranging over a 2 orders of magnitude range are given in Figure 8 . At the highest $\mathrm{NaCl}(\mathrm{aq})$ concentrations of 3.4 and $2 \mathrm{M}$, employed in this investigation (curves $\mathrm{i}$ and ii respectively), breakdown occurs within seconds and consequently $E_{b}$ is determined by the initial value of $E_{\text {corr }}$ at $t=0$. When $\left[\mathrm{Cl}^{-}\right]$is progressively decreased at more dilute concentrations of $\leq 0.86 \mathrm{M}$, there is an increased delay time prior to breakdown, as evidenced by the arrows which indicate filiform-like initiation on each of the $\mathrm{E}_{\text {corr }}$ transients in Figure 8, plots iii - vi. Immersion in a $0.86 \mathrm{M} \mathrm{NaCl}(\mathrm{aq})$ electrolyte leads to passivity breakdown within ca. 15 min (curve iii), but takes up to 150 $\min$ in a $0.034 \mathrm{M}$ concentration. Correspondingly, it is also evident from the same family of plots that the $E_{\text {corr }}$ value marking the point of breakdown $\left(E_{b}\right)$ is also shifted to progressively more positive values with decreasing $\left[\mathrm{Cl}^{-}\right]$, as previously observed for both pure $\mathrm{Mg}$ and $\mathrm{AZ31}{ }^{40}$. Values of $E_{b}$ determined from the various $\mathrm{E}_{\text {corr }}$ vs time curves given in Figure 8 were subsequently plotted as a function of chloride ion concentration and showed a clear dependence on $\left[\mathrm{Cl}^{-}\right]$according to the equation (1) below.

$$
E_{b}=A+B \log _{10}\left[\mathrm{Cl}^{-}\right]
$$


The constant $A$ equates to the value of $E_{b}$ determined at a chloride ion concentration of $1 \mathrm{M}$, while $B$ is a constant that depends on both the type of alloy and corrosive electrolyte. Under the conditions employed here, values of $-1.66 \mathrm{~V}$ and $-0.077 \mathrm{~V} /$ decade were obtained for $\mathrm{A}$ and $\mathrm{B}$ respectively for E717, which is in good agreement with values of $-1.59 \mathrm{~V}$ and $-0.072 \mathrm{mV} /$ decade determined previously for AZ31 over a similar range of chloride concentration using the same methodology ${ }^{40}$ at neutral $\mathrm{pH}$. This similarity with AZ31 implies that the value of B does not significantly depend on alloy composition, but rather on the nature of the protective magnesium(hydroxide) film formed in neutral aqueous solution.

Others have previously reported a dependence of the anodic branches of potentiodynamic polarisation data on sodium chloride concentration in the $0.016-1.6 \% \mathrm{w} / \mathrm{v}$ range for ZEK100 (generic E717 alloy type) substrates in neutral electrolyte ${ }^{17}$. Although the studies described here demonstrate that spontaneous breakdown in the absence of external polarisation is observed at the highest concentrations in this range, this previously published study ascribes inflections in the anodic current versus applied potential curves to a breakdown potential ( $\left.E_{b}\right)$, and demonstrates that these values become more positive with decreasing chloride ion concentration. A reworking of the data presented therein gave a linear plot of $E_{b}$ versus $\log _{10}\left[\mathrm{Cl}^{-}\right]$with a slope of $0.072 \mathrm{~V}$ per decade, which is in good agreement with the value obtained in this present study, using time-dependent $E_{c o r r}$ data to determine values of $E_{b}$. This potentiodynamic polarisation investigation of $E 717$ chloride ion concentration dependence has been extended here to include conditions of elevated $\mathrm{pH}$ (in this case $\mathrm{pH} 11$ ), where the $\mathrm{Mg}$ matrix would be expected to exhibit passivity ${ }^{46}$. In the range of concentrations used here $\left(10^{-2}\right.$ to $\left.0.86 \mathrm{M}\right)$, immersion of E717 specimens under freely corroding conditions at a pH of $11 \mathrm{produced}$ no visual evidence of breakdown for periods of up to 6h. Typical polarization curves obtained over this [NaCl] range at pH 11 are shown in Figure 9 a. Prior to the start of polarisation, each solution was purged with air for 15 min in order to minimise any potential interference from carbonate species formed as a result of dissolved carbon dioxide. At $[\mathrm{NaCl}] \leq 0.034 \mathrm{M}$, clear inflections in the anodic branches of curves iii and iv are observed in Figure $9 a$, signifying passivity breakdown and consequently $E_{b}$ can be conveniently identified as the point of a sharp increase in current density with applied potential. For concentrations $\geq 0.17 \mathrm{M}$, determination of $E_{b}$ was less certain and consequently the potential at which current density exceeded a threshold of $1 \mathrm{~mA} \mathrm{~cm}^{-2}$ was assumed to constitute the breakdown potential. Figure $9 \mathrm{~b}$ shows mean values of Eb determined in 3 repeat experiments (plot i), along with $\mathrm{E}_{\text {corr }}$ values measured over 10 min prior to the start of potentiodynamic polarisation (plot ii), plotted as a function of log ${ }_{10}\left[\mathrm{Cl}^{-}\right]$. Under conditions of elevated $\mathrm{pH}$ used for these experiments, values of $-1.63 \mathrm{~V}$ and $-0.15 \mathrm{~V} /$ decade were obtained for $\mathrm{A}$ and $\mathrm{B}$ respectively. $\mathrm{E}_{\text {corr }}$ is also shown to decrease with increasing $\left[\mathrm{Cl}^{-}\right]$, with a reduced gradient of ca. $-0.05 \mathrm{~V} /$ decade. At the point where plots i and ii intersect (i.e where $\mathrm{E}_{\text {corr }}$ $=E_{b}$, indicated by the downward arrow) spontaneous breakdown in the absence of external polarization would be anticipated, and under the conditions employed here, this is predicted to occur at a chloride ion concentration of ca. $1.5 \mathrm{M}$. It should be noted that the value of B obtained from potentiodynamic measurements at elevated $\mathrm{pH}$ is significantly higher than when determined using $\mathrm{E}_{\mathrm{corr}}$ vs time data under neutral conditions. The underlying reasons are unclear, given the previous finding for pure $\mathrm{Mg}$ that similar values of $\mathrm{ca}-0.11 \mathrm{~V} /$ decade were established using both methods 40. However, the $\mathrm{pH}$ dependence of B may be due to the presence of alloying additions such as $\mathrm{Zn}$, which would not be predicted to maintain passivity in the same manner as $\mathrm{Mg}$ at elevated $\mathrm{pH}^{46}$.

Finally, a series of immersion experiments were conducted, using a range of $\mathrm{NaCl}(\mathrm{aq})$ concentrations in the $10^{-3}-0.86 \mathrm{M}$ range at $\mathrm{pH} 6$, to determine the influence of $\left[\mathrm{Cl}^{-}\right]$on bulk corrosion rates, as measured using volumetric hydrogen gas capture. The principal aim was to correlate bulk corrosion rates with the trends observed using quantitative SVET data. Figure 10 shows data obtained for E717 specimens, converted to areaaveraged moles of $\mathrm{H}_{2}$ evolved, plotted as a function of immersion time at various [ $\left.\mathrm{NaCl}\right]$. Over the $10 \mathrm{~h}$ timescale of the experiments, the hydrogen evolution rate is negligible at $[\mathrm{NaCl}] \leq 0.034 \mathrm{M}$ (plots iv and $\mathrm{v}$ ), reflecting the fact that although spontaneous breakdown can occur, a considerable delay is observed prior to visual evidence of filiform-like propagation. At $[\mathrm{NaCl}] \geq 0.17 \mathrm{M}$ (plots $\mathrm{i}-\mathrm{iii}$ ), there is a progressive increase in $\mathrm{H}_{2}$ evolution rate with increasing concentration, while the linear relationship of moles $\mathrm{H}_{2}$ with immersion time allows an area normalised cathodic current to be 
calculated at each different concentration. Values of $0.2,0.35$ and $0.55 \mathrm{~A} \mathrm{~m}^{-2}$ can be derived for E717 specimens immersed in $0.17,0.6$ and $0.86 \mathrm{M}$ $\mathrm{NaCl}(\mathrm{aq})$ respectively. For the corresponding SVET data obtained at the highest of these concentrations (0.86 M), numerical integration of cathodic current density distributions (see maps shown in Figure 4) to produce an area averaged total cathodic current per scan, gave a constant value of 0.42 $A \mathrm{~m}^{-2}$ over a $8 \mathrm{~h}$ immersion period following an initial period of stabilisation. The underestimation of hydrogen evolution rate by numerical integration of SVET data has been demonstrated elsewhere ${ }^{31}$, and is explained by the fact that the technique cannot detect local cathode sites which are colocated at, or immediately behind, the principal sites of anodic magnesium dissolution. Also included in Figure 10 for comparison is the area normalised hydrogen evolution rate for AZ31B obtained in $0.86 \mathrm{M} \mathrm{NaCl}$ (aq) electrolyte, showing a significantly higher slope than observed for E717 under the same conditions. A previous SVET-based investigation of this particular alloy reported significantly higher peak anodic and cathodic current density values determined at localized corrosion sites than measured here for E717 under the same conditions ${ }^{24}$. Consequently, the higher corrosion resistance of E717 in comparison to AZ31 under freely corroding conditions can, in part, be correlated to a significantly lower extent of cathodic activation produced by prior anodic dissolution.

\section{CONCLUSIONS}

- The influence of the chloride ions concentration on localized corrosion propagation of E717 Mg alloy was investigated using a scanning vibrating electrode technique in conjunction with time-lapse imaging. The alloy undergoes a filiform-like localized corrosion with the leading edge of the filaments being intense focal anodes, which move over the surface leaving a cathodically-activated dark surface behind.

- A progressive increase in concentration leads to a more rapid propagation of filiform-like corrosion features as quantified by plots of corroded area versus immersion time. Two distinct phases in filiform-like propagation, comprising an initial slower development of discrete individual filaments, followed by a more rapid growth of uniform corrosion front. The time taken to transition from phase 1 to phase 2 progressively decreases with increasing electrolyte concentration. Typical peak current density associated with local anodes progressively increases with chloride ion concentration, demonstrating the importance of galvanic coupling with cathodically activated regions over the entirety of the exposed $\mathrm{Mg}$ alloy surface.

- When the electrolyte concentration $\geq 0.034 \mathrm{M}$ the breakdown of the surface occurs spontaneously at neutral $\mathrm{pH}$ and in the absence of external polarisation. A breakdown potential $\left(E_{b}\right)$ and can be identified by following time-dependent $E_{\text {corr }}$ behaviour and is shown to vary as a function of $\log _{10}\left[\mathrm{Cl}^{-}\right]$with a slope of $0.077 \mathrm{~V} /$ decade, which is in good agreement with previous studies of other $\mathrm{Mg}$ alloys.

- Trends observed by numerically integrating SVET-derived current density distributions were confirmed by measuring volumetrically the hydrogen evolved from the alloy surface over a range of different electrolyte concentrations. Area averaged cathodic current densities estimated from bulk hydrogen evolution rates were shown to be $20 \%$ greater than those determined from SVET data. The difference was ascribed to cathodic hydrogen evolution at the principal sites of $\mathrm{Mg}$ dissolution, revealed as net local anodes, which remains undetected by SVET. 


\section{ACKNOWLEDGMENTS}

The support of BASF's Coatings division and Swansea University's EPSRC-funded Centre for Doctoral Training in advanced functional coatings (COATED2), administered through the Materials and Manufacturing Academy, is gratefully acknowledged.

\section{REFERENCES}

1. M.K. Kulekci, Int. J. Adv. Manuf. Technol. 39 (2008): p. 851-865.

2. T.W. Skszek, M. Zaluzec, J. Conklin, and D. Wagner, “MMLV: Project Overview," in SAE Tech. Pap. (2015).

3. A.A. Luo, Int. Mater. Rev. 49 (2004): p. 13-30.

4. B. Smola, I. Stulíková, J. Pelcová, and B.L. Mordike, J. Alloys Compd. 378 (2004): p. 196-201.

5. Y. Fan, G. Wu, H. Gao, G. Li, and C. Zhai, J. Mater. Sci. 41 (2006): p. 5409-5416.

6. Y.L. Song, Y.H. Liu, S.R. Yu, X.Y. Zhu, and S.H. Wang, J. Mater. Sci. 42 (2007): p. 4435-4440.

7. T.J. Luo, Y.S. Yang, Y.J. Li, and X.G. Dong, Electrochim. Acta 54 (2009): p. 6433-6437.

8. W. Liu, F. Cao, L. Zhong, L. Zheng, B. Jia, Z. Zhang, and J. Zhang, Mater. Corros. 60 (2009): p. 795-803.

9. J.W. Chang, X.W. Guo, P.H. Fu, L.M. Peng, and W.J. Ding, Electrochim. Acta 52 (2007): p. 3160-3167.

10. J.W. Chang, L.M. Peng, X.W. Guo, A. Atrens, P.H. Fu, W.J. Ding, and X.S. Wang, J. Appl. Electrochem. 38 (2008): p. 207-214.

11. T.A. Huehnerschulte, N. Angrisani, D. Rittershaus, D. Bormann, H. Windhagen, and A. MeyerLindenberg, Materials (Basel). 4 (2011): p. 1144-1167.

12. H. Waizy, A. Weizbauer, C. Modrejewski, F. Witte, H. Windhagen, A. Lucas, M. Kieke, B. Denkena, P. Behrens, A. Meyer-Lindenberg, F.-W. Bach, and F. Thorey, Biomed. Eng. Online 11 (2012): p. 12.

13. T.A. Huehnerschulte, J. Reifenrath, B. von Rechenberg, D. Dziuba, J.M. Seitz, D. Bormann, H. Windhagen, and A. Meyer-Lindenberg, Biomed. Eng. Online 11 (2012): p. 14.

14. D. Dziuba, A. Meyer-Lindenberg, J.M. Seitz, H. Waizy, N. Angrisani, and J. Reifenrath, Acta Biomater. 9 (2013): p. 8548-8560.

15. J. Zhao, L.-L. Gao, H. Gao, X. Yuan, and X. Chen, Fatigue Fract. Eng. Mater. Struct. 38 (2015): p. $904-913$.

16. Q. Li, W. Ye, H. Gao, and L. Gao, Mater. Des. 181 (2019): p. 107933.

17. R.M. Asmussen, W.J. Binns, P. Jakupi, and D. Shoesmith, Corrosion 71 (2014): p. 242-254.

18. W. Jeffrey Binns, F. Zargarzadah, V. Dehnavi, J. Chen, J.J. Noël, and D.W. Shoesmith, CORROSION 75 (2019): p. 58-68.

19. M.P. Brady, G. Rother, L.M. Anovitz, K.C. Littrell, K.A. Unocic, H.H. Elsentriecy, G.-L. Song, J.K. Thomson, N.C. Gallego, and B. Davis, J. Electrochem. Soc. 162 (2015): p. C140-C149.

20. M.P. Brady, M. Fayek, D.N. Leonard, H.M. Meyer, J.K. Thomson, L.M. Anovitz, G. Rother, G.-L. Song, and B. Davis, J. Electrochem. Soc. 164 (2017): p. C367-C375.

21. G. Williams, C. Kousis, N. McMurray, and P. Keil, Npj Mater. Degrad. 3 (2019): p. 41.

22. L. Wang, T. Shinohara, and Z. B.-P. Zhang, J. Solid State Electrochem. 14 (2010): p. 1897-1907.

23. A. Samaniego, I. Llorente, and S. Feliu, Corros. Sci. 68 (2013): p. 66-71.

24. G. Williams, H. ap Llwyd Dafydd, and R. Grace, Electrochim. Acta 109 (2013): p. 489-501.

25. O. Lunder, J.E. Lein, S.M. Hesjevik, T.K. Aune, and K. Nişancioğlu, Mater. Corros. 45 (1994): p. 331-340.

26. P. Schmutz, V. Guillaumin, R.S. Lillard, J.A. Lillard, and G.S. Frankel, J. Electrochem. Soc. 150 (2003): p. B99.

27. G. Williams and R. Grace, Electrochim. Acta 56 (2010): p. 1894-1903.

28. G. Williams, N. Birbilis, and H.N. McMurray, Faraday Discuss. 180 (2015): p. 313-330.

29. G. Williams, K. Gusieva, and N. Birbilis, Corrosion 68 (2012): p. 489-498. 
30. J.R. Kish, G. Williams, J.R. McDermid, J.M. Thuss, and C.F. Glover, J. Electrochem. Soc. 161 (2014): p. C405-C411.

31. E. Michailidou, H.N. McMurray, and G. Williams, J. Electrochem. Soc. 165 (2018): p. C195-C205.

32. S. V Lamaka, D. Höche, R.P. Petrauskas, C. Blawert, and M.L. Zheludkevich, Electrochem. Commun. 62 (2016): p. 5-8.

33. D. Höche, C. Blawert, S. V Lamaka, N. Scharnagl, C. Mendis, and M.L. Zheludkevich, Phys. Chem. Chem. Phys. 18 (2016): p. 1279-1291.

34. R. Bolton, T. Dunlop, J. Sullivan, J. Searle, H. Heinrich, R. Westerwaal, C. Boelsma, and G. Williams, J. Electrochem. Soc. 166 (2019): p. C3305-C3315.

35. G. Wu, Y. Fan, A. Atrens, C. Zhai, and W. Ding, J. Appl. Electrochem. 38 (2008): p. 251-257.

36. M. Zhao, M. Liu, G. Song, and A. Atrens, Corros. Sci. 50 (2008): p. 3168-3178.

37. F. El-Taib Heakal, A.M. Fekry, and M.Z. Fatayerji, Electrochim. Acta 54 (2009): p. 1545-1557.

38. L. Wang, T. Shinohara, and B.-P. Zhang, J. Alloys Compd. 496 (2010): p. 500-507.

39. F. El-Taib Heakal, A.M. Fekry, and M. Abd El-Barr Jibril, Corros. Sci. 53 (2011): p. 1174-1185.

40. G. Williams, H. Ap Llwyd Dafydd, R. Subramanian, and H.N. McMurray, Corrosion 73 (2017): p. 471-481.

41. G. Williams and H.N. McMurray, Corrosion 62 (2006): p. 231-242.

42. G. Williams and H. Neil McMurray, J. Electrochem. Soc. 155 (2008): p. C340.

43. H.S. Isaacs, J. Electrochem. Soc. 138 (1991): p. 722.

44. Z.P. Cano, M. Danaie, J.R. Kish, J.R. McDermid, G.A. Botton, and G. Williams, CORROSION 71 (2015): p. 146-159.

45. S.H. Salleh, S. Thomas, J.A. Yuwono, K. Venkatesan, and N. Birbilis, Electrochim. Acta 161 (2015): p. 144152.

46. M. Pourbaix, Atlas of Electrochemical Equilibria in Aqueous Solutions (Oxford: Pergamon Press, 1966). 


\section{FIGURE CAPTIONS}

FIGURE 1: SVET-TLI derived current density distribution maps with associated photographic images recorded for a corroding E717 magnesium alloy surface obtained after (a) $200 \mathrm{~min}$, (b) $370 \mathrm{~min}$, (c) $630 \mathrm{~min}$, (d) $820 \mathrm{~min}$,(e) $930 \mathrm{~min}$ and (f) 24 hours immersion in aerated $0.034 \mathrm{M} \mathrm{NaCl}$ (aq).

FIGURE 2: As figure 1, except that an aerated $0.17 \mathrm{M} \mathrm{NaCl}$ (aq) solution was used. Time key: (a) $100 \mathrm{~min}$, (b) $120 \mathrm{~min}$, (c) $380 \mathrm{~min}$, (d) $420 \mathrm{~min}$, (e) 510 min and (f) 24 hours immersion.

FIGURE 3: Local current density $\left(\mathrm{j}_{2}\right)$ versus distance profiles plotted for a propagating filiform-like corrosion feature observed for an E717 specimen immersed in $0.17 \mathrm{M} \mathrm{NaCl}$ (aq). Time key: plot (i) $340 \mathrm{~min}$, with (ii) - (iv) obtained at 15 min intervals thereafter.

FIGURE 4: As figure 1, except that an aerated $0.86 \mathrm{M} \mathrm{NaCl}$ (aq) solution was used. Time key: (a) $40 \mathrm{~min}$, (b) $200 \mathrm{~min}$, (c) $280 \mathrm{~min}$, (d) $510 \mathrm{~min}$, (e) 12 hours and (f) 24 hours immersion

FIGURE 5: Plots of corroded area, estimated from visual image analysis, as a function of immersion time for freely corroding E717 samples held in (i) 0.86. (ii) 0.17 and (iii) $0.034 \mathrm{M}$ aerated solutions of $\mathrm{NaCl}$ (aq) at $\mathrm{pH} 6.5$.

FIGURE 6: Area-averaged total anodic current density values calculated by numerical integration of SVET- derived current density distribution maps plotted as a function of time for E717 specimens immersed in aerated aqueous $\mathrm{NaCl}$ electrolyte at concentrations of (i) $0.86 \mathrm{M}$, (ii) $0.17 \mathrm{M}$ and (iii) $0.034 \mathrm{M}$.

FIGURE 7: Time-dependent $\mathrm{E}_{\text {corr }}$ variation (a) observed for freely corroding $\mathrm{E} 717$ immersed in $0.17 \mathrm{M} \mathrm{NaCl}(\mathrm{aq})$ at pH 6.5, correlated with both photographic images and SVET-derived current density distribution maps of the corroding surface obtained at intervals of (b) 100 min and (c) 180 min following initial immersion.

FIGURE 8: Plots of $\mathrm{E}_{\text {corr }}$ versus time obtained for $\mathrm{E} 717$ specimens immersed in pH 6.5, aerated $\mathrm{NaCl}$ (aq) electrolyte at concentrations of: (i) $3.4 \mathrm{M}$, (ii) $2 \mathrm{M}$, (iii) $0.86 \mathrm{M}$, (iv) $0.6 \mathrm{M}$, (v) $0.17 \mathrm{M}$ and (vi) $0.034 \mathrm{M}$. The arrows indicate the point of passivity breakdown in each case.

FIGURE 9: (a) Anodic-going potentiodynamic polarization curves obtained for $\mathrm{E} 717$ in $\mathrm{NaCl}$ (aq) solutions at concentrations of (i) $0.86 \mathrm{M}$, (ii) $0.17 \mathrm{M}$, (iii) $0.034 \mathrm{M}$ and (iv) $10^{-2} \mathrm{M}$ at pH 11 in aerated conditions at room temperature. A sweep rate of $1 \mathrm{mV} / \mathrm{s}$ was used in each case. (b) shows a summary plot of (i) breakdown potential $\left(E_{b}\right)$ and (ii) free corrosion potential ( $\left.E_{\text {corr }}\right)$ versus chloride ion concentration determined for $E 717$ specimens in $\mathrm{NaCl}$-containing electrolyte at $\mathrm{pH} 11$.

FIGURE 10: Plots of moles hydrogen gas per unit area evolved versus time for $\mathrm{E} 717$ immersed under freely corroding conditions in $\mathrm{NaCl}$ (aq) at $\mathrm{pH}$ 6: (i) $0.86 \mathrm{M}$, (ii) $0.6 \mathrm{M}$, (iii) $0.17 \mathrm{M}$, (iv) $0.034 \mathrm{M}$ and (v) $10^{-3} \mathrm{M}$, while plot (vi) shows data obtained for AZ31B upon immersion in $0.86 \mathrm{M} \mathrm{NaCl}$ (aq). 
Figure 1

(a)
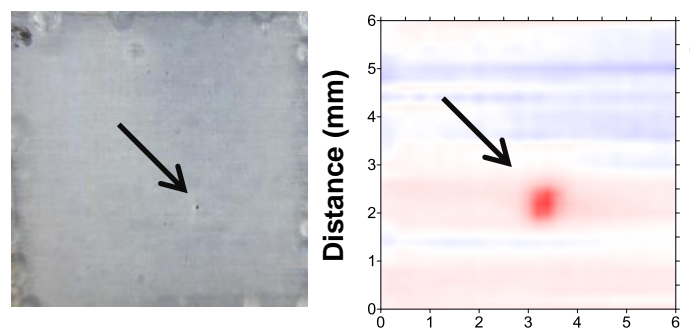

(c)

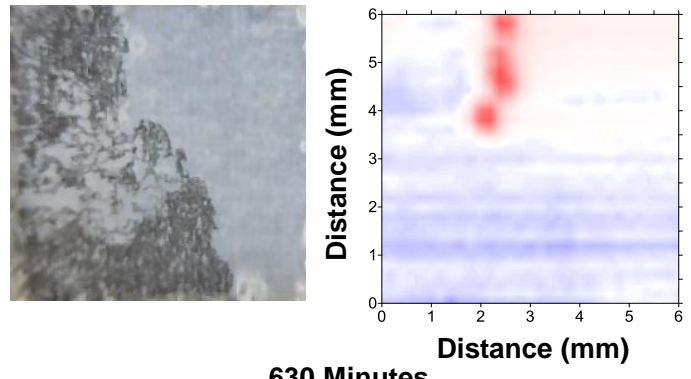

(e)

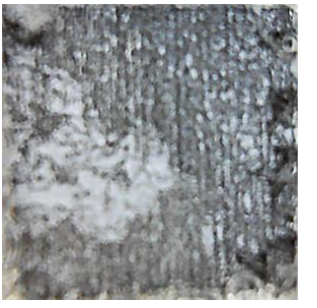

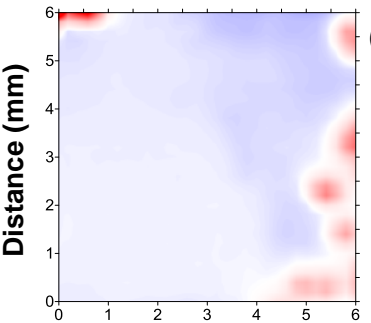

Distance (mm) (b)
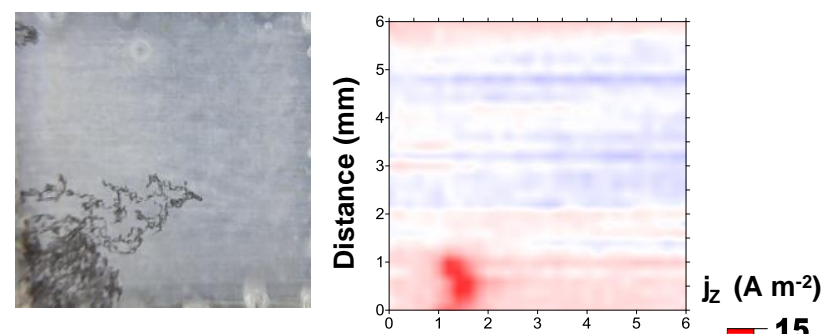

(d)

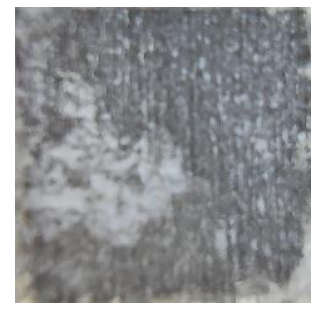

370 Minutes

Distance (mm)

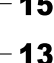

13

11

9

7

5

3

1

$-1$

820 Minutes
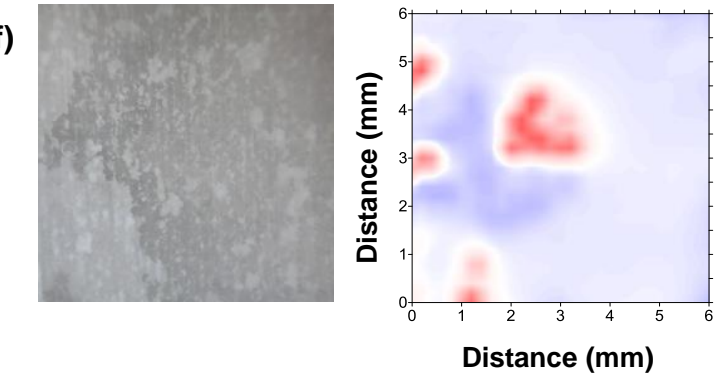

24 Hours

Distance (mm) 
Figure 2

(a)

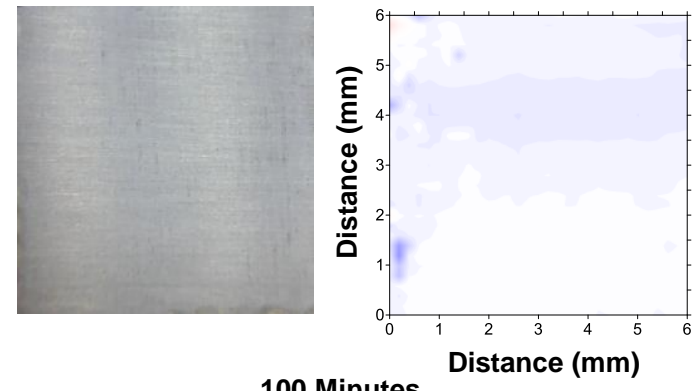

(c)
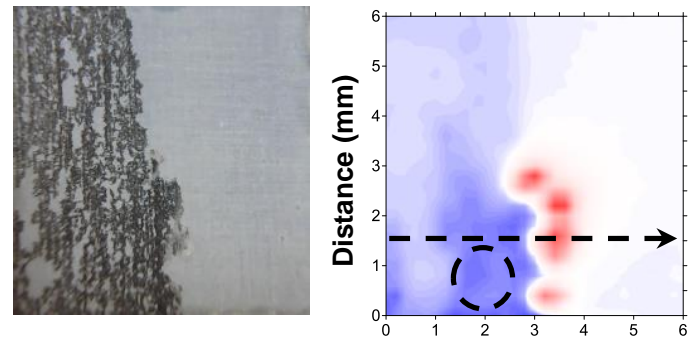

380 Minutes

(e)

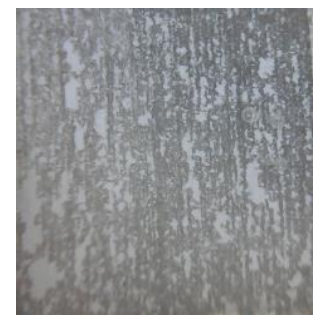

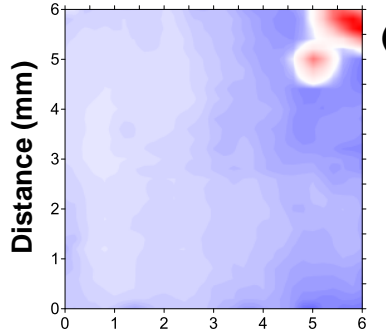

Distance (mm) (b)
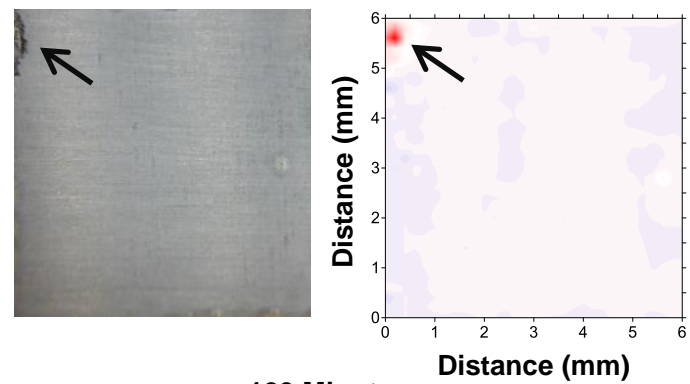

$\mathrm{j}_{\mathrm{z}}\left(\mathrm{A} \mathrm{m}^{-2}\right)$

(d)
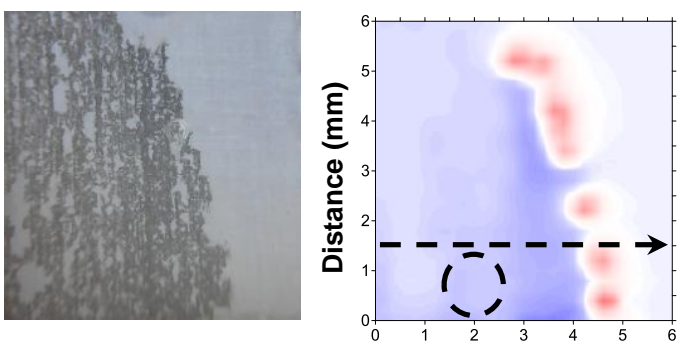

Distance (mm)

420 Minutes

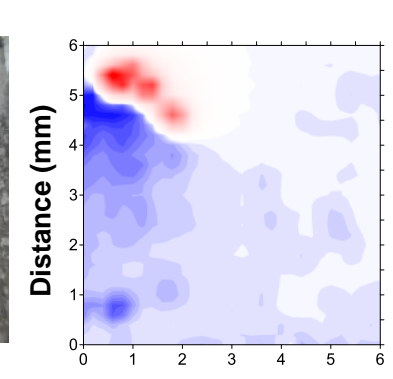

Distance (mm) (f)

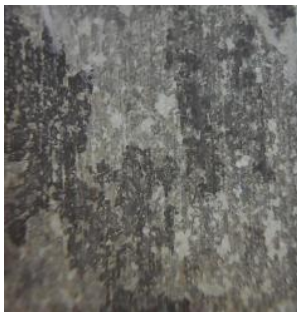

24 Hours 
Figure 3

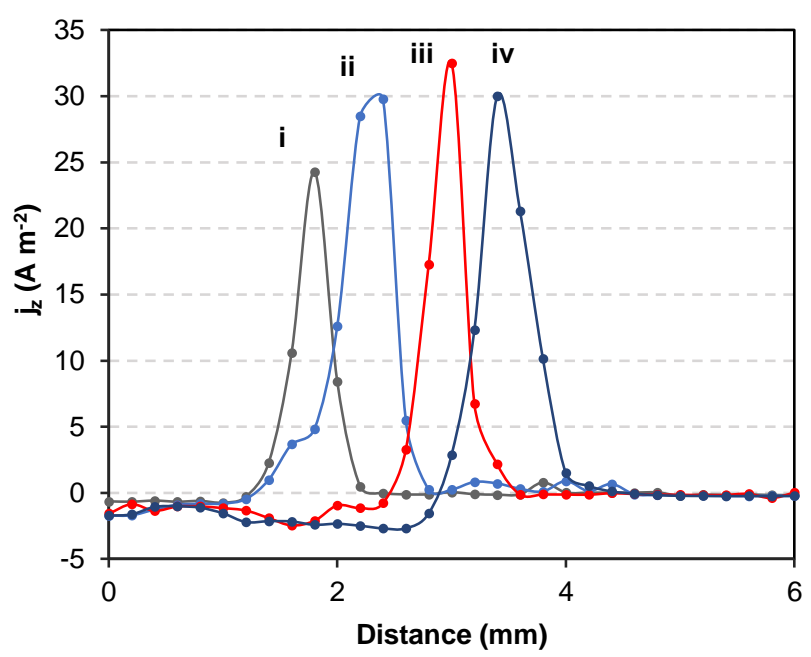


Figure 4

(a)
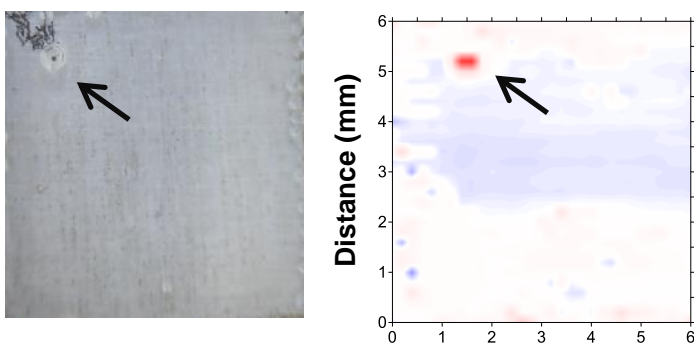

40 Minutes

(c)
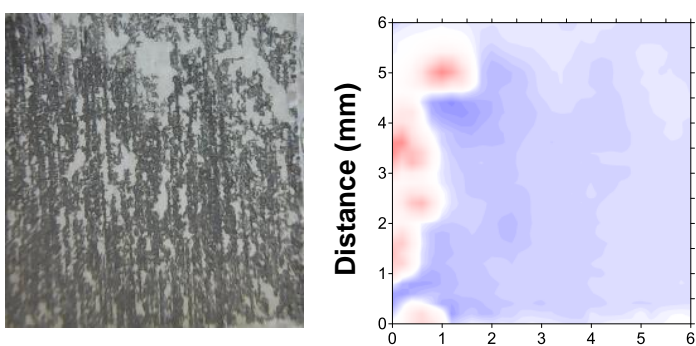

280 Minutes

Distance $(\mathrm{mm})$

(e)
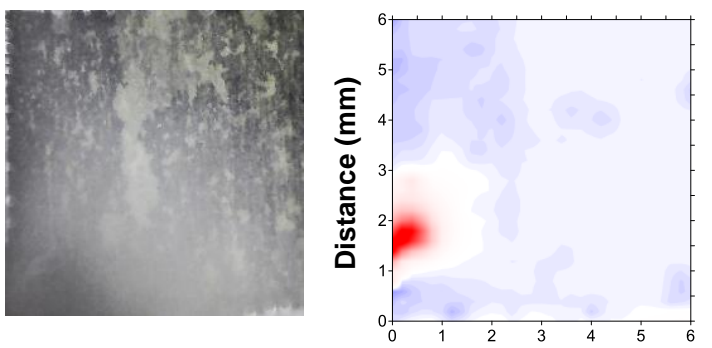

12 Hours (b)
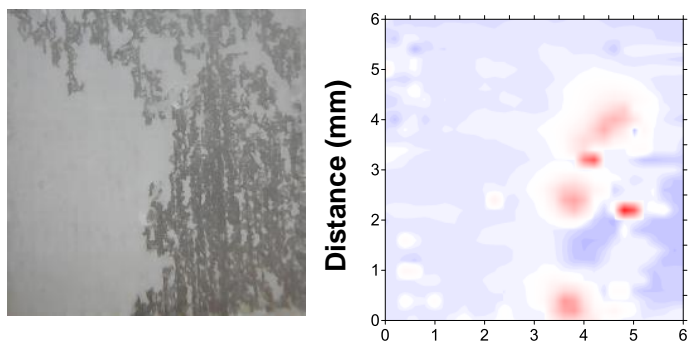

$\mathrm{j}_{\mathrm{z}}\left(\mathrm{A} \mathrm{m}^{-2}\right)$ 100 90

(d)

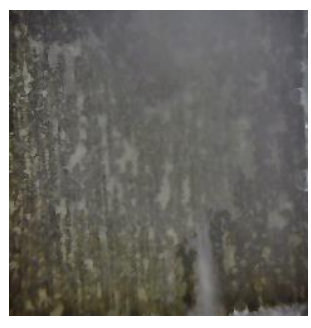

200 Minutes

Distance (mm)

80

70

60

50

40

30

20

10

0

$-10$

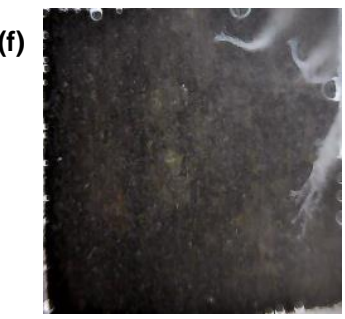

510 Minutes

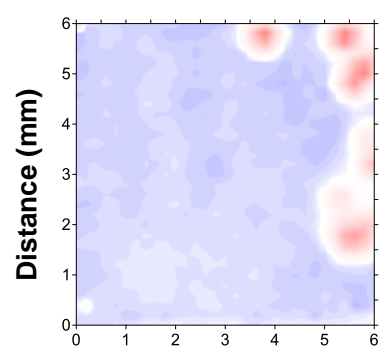

24 Hours

Distance $(\mathrm{mm})$ 
Figure 5

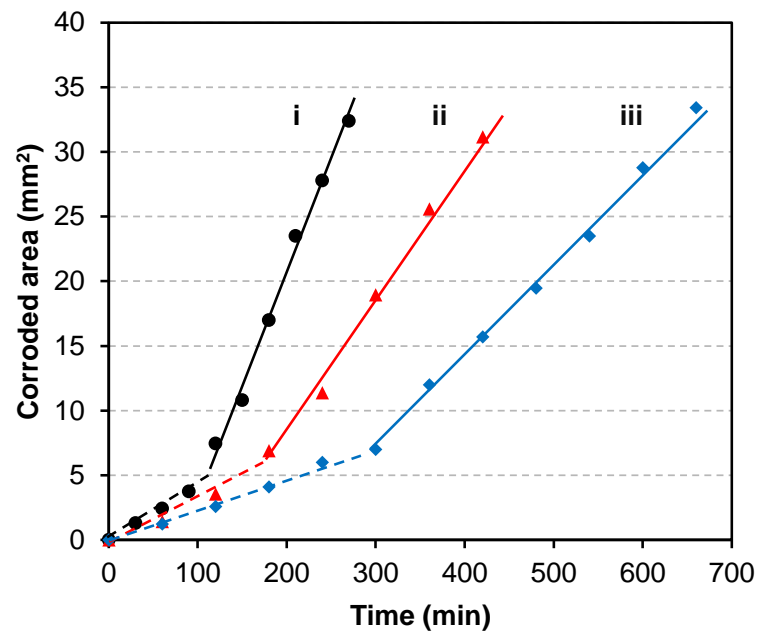


Figure 6

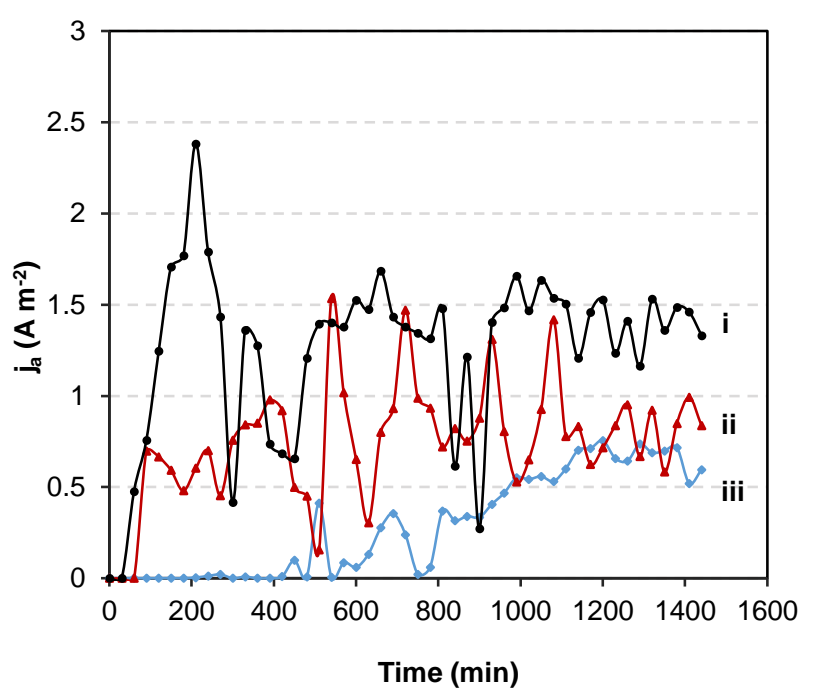


Figure 7
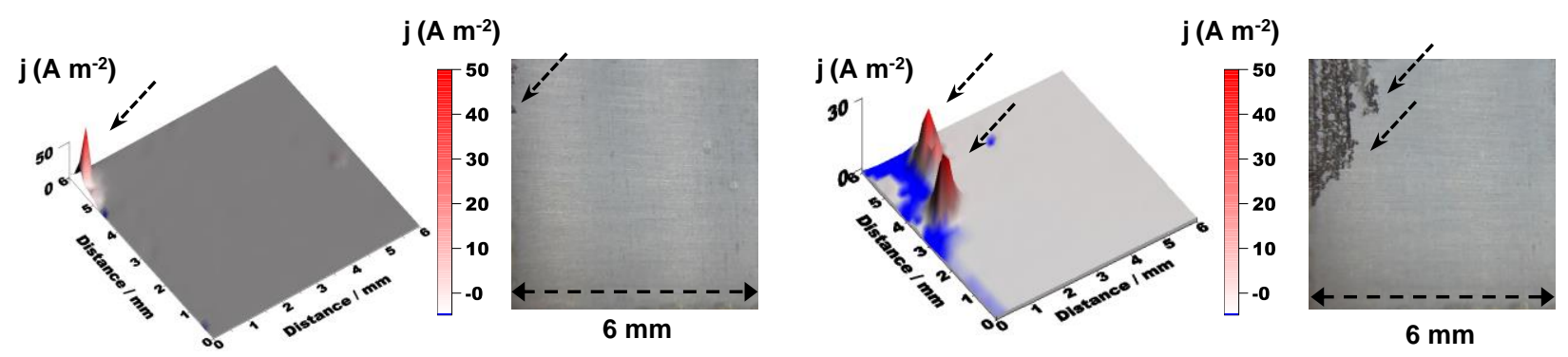

(b)

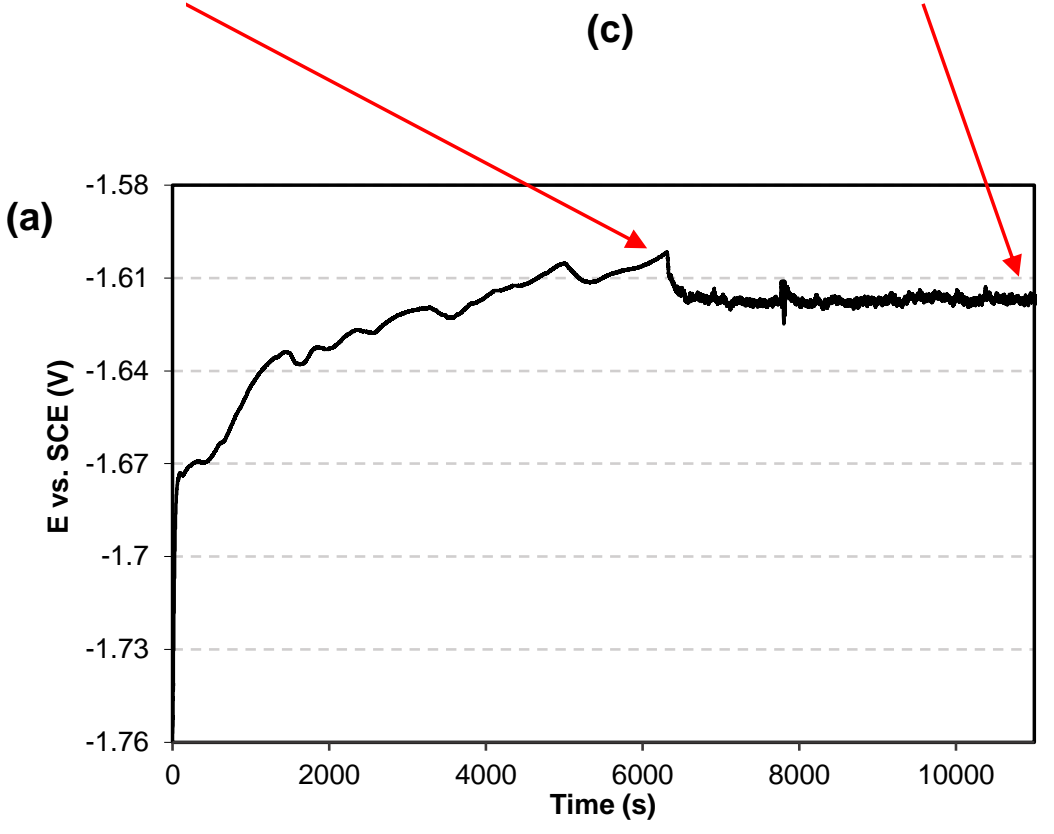


Figure 8

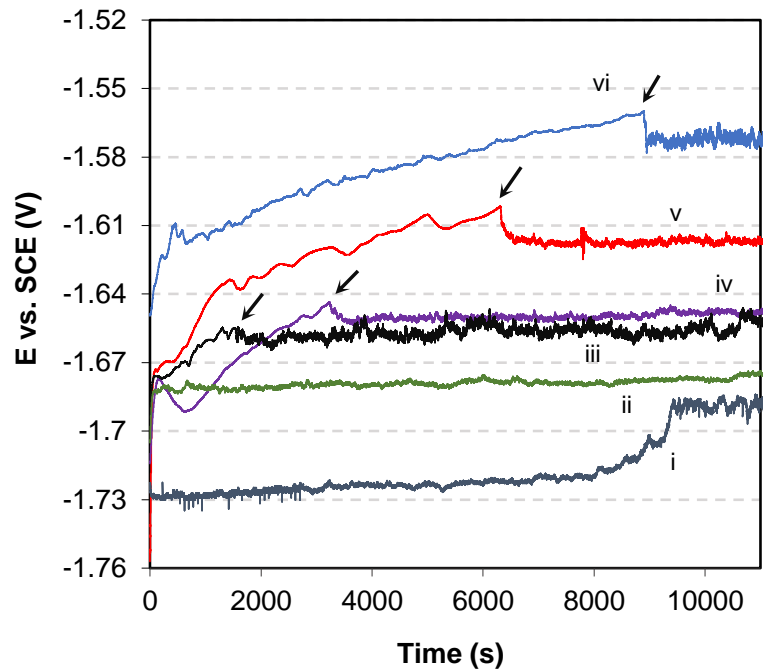


Figure 9a

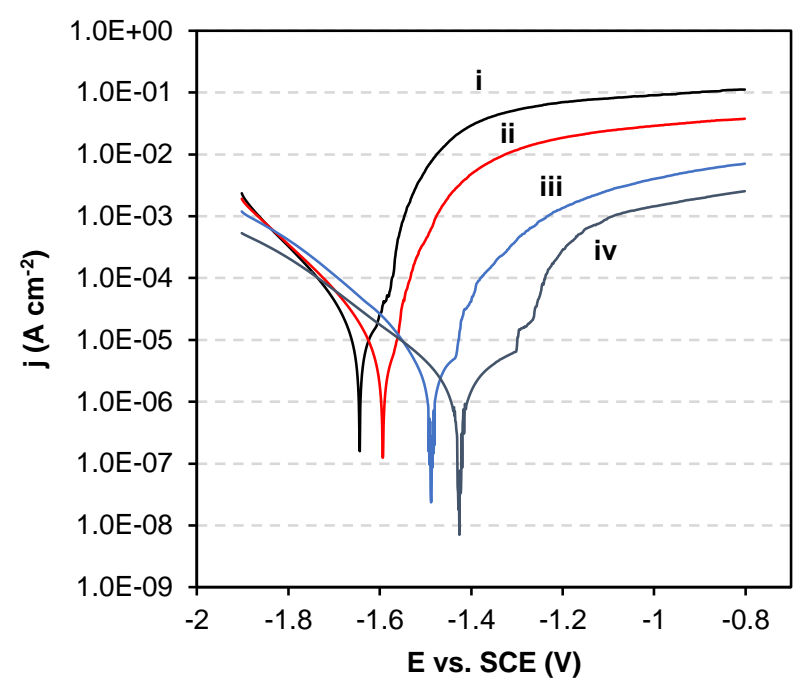


Figure 9b

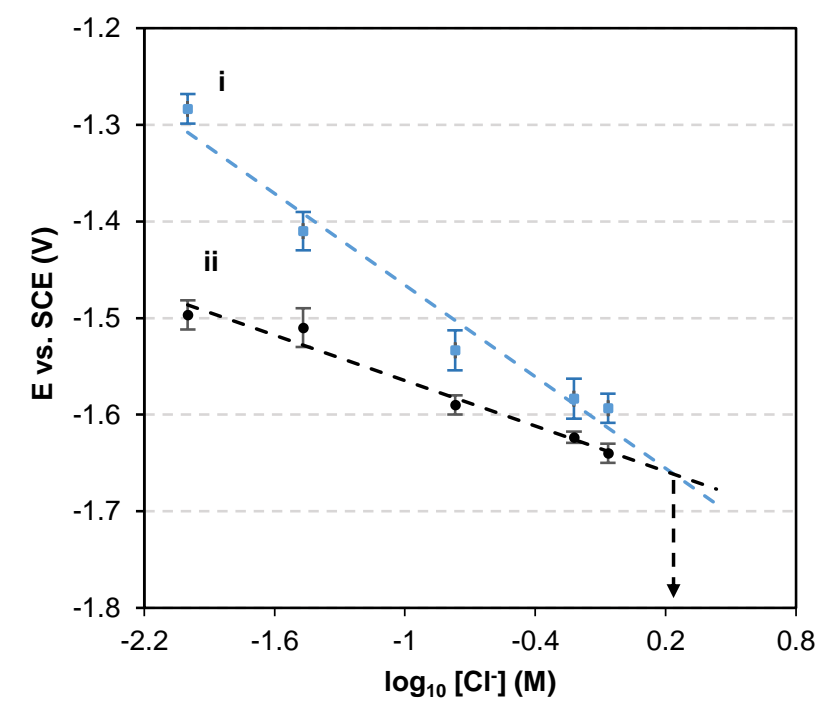


Figure 10

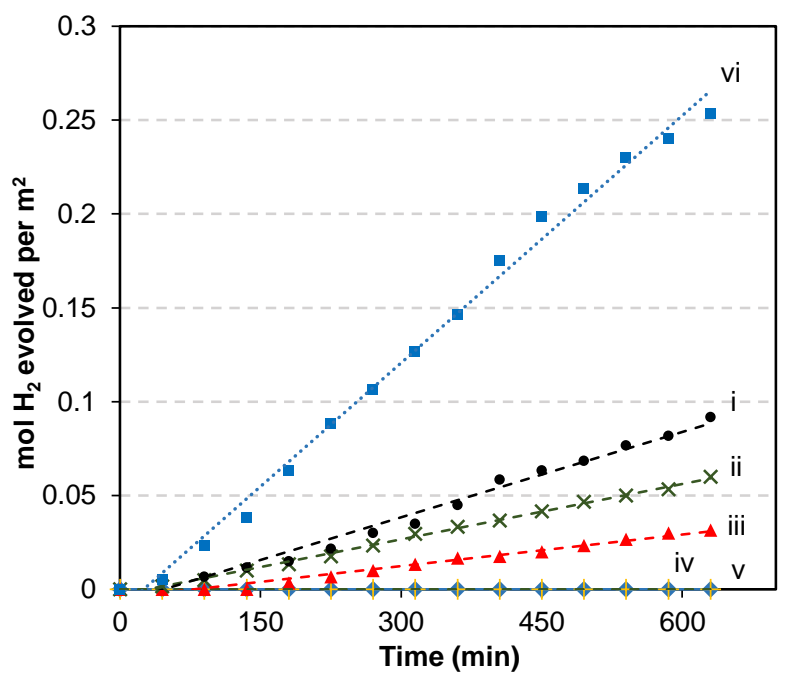

